\title{
Primeras ascensiones en globo en la ciudad de México: un empresario de espectáculos (1833-1835)
}

Ana Lau Jaiven

INSTITUTO MORA

Cómo se contrataban las diversiones en la primera mitad del siglo XIX, y cómo eran las relaciones entre el Ayuntamiento capitalino y los empresarios y cómo el público salía defraudado.

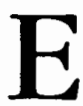
1 tema de este trabajo gira alrededor de un incidente en la carrera empresarial del general Manuel Barrera, el más conocido y comentado y que, por lo mismo, ha pasado a ser referencia obligada cuando se habla de las diversiones públicas en la ciudad de México durante la primera mitad del siglo XIX. Autores como Enrique de Olavarría y Ferrari, Luis Reyes de la Maza, Armando de Maria y Campos y Roberto Moreno ${ }^{1}$ han

\footnotetext{
'Olavarría y Ferrari, Reseña, 1895, vol. I; Moreno, "Primeros", 1993; Reyes de la Maza, Teatro, 1969.
}

escrito largos y circunstanciados relatos acerca de las ascensiones aerostáticas, no obstante, la mención de Barrera como uno de los protagonistas involucrados en los sucesos, no ha sido suficientemente documentada a causa del desconocimiento que ronda alrededor de este controvertido personaje. Esos autores apenas dejan entrever su actividad como empresario y habilitador de espectáculos populares y, podríamos decir, masivos, según los parámetros actuales, en donde dos aeronautas extranjeros protagonizaron el intento de surcar los aires de nuestra ciudad capital. 
El objetivo de este trabajo reside en analizar la manera en que se realizaban estos espectáculos públicos, de ahí que hablaré de los costos, de las funciones y de las pugnas que se suscitaron entre Barrera y los aeronautas y entre él y el Ayuntamiento de la ciudad, amén de relatarles lo que sucedió. En este sentido, el tema del espectáculo resulta interesante para explicar y conocer cómo las diversiones públicas fueron consideradas un pingüe negocio que produjo a empresarios, como Barrera, grandes ganancias, obtenidas muchas veces de manera fraudulenta.

\section{LOS ACTORES}

Los protagonistas del evento fueron en este caso, por un lado, el general Manuel Barrera Dueñas, empresario que contrató el espectáculo; el Ayuntamiento de la ciudad de México entre los años de 1833 y 1835 y dos aeronautas de origen francés, Adolphe Theodore y Eugenio Robertson. Theodore, originario de Lyon, residía entonces en Cuba, donde se decía que había ascendido en globo en cinco ocasiones; también se añadía que las ganancias por presenciar el espectáculo del francés habían sido enormes. El segundo aeronauta, Guillermo Eugenio Robertson, era francés de origen pero avecindado en Estados Unidos, y llevaba en su haber 21 ascensiones; además, venía precedido de la fama de ser hijo de Etienne Gaspard Robertson (1763-1837), otro famoso aeronauta muy conocido por sus hazañas. Cabe mencionar que, antes de que se llevara a cabo el acto de Eugenio Robertson, se pensó en documentar las pericias del aeronauta para lograr atraer el interés de la gente que asistiera a la función, "se publicó un librito con la traducción (hecha por el poeta cubano Heredia) de las descripciones de sus viajes aéreos que parecen haber gozado de mucho éxito de ventas". ${ }^{2}$

En lo que respecta a los espectáculos, el Estado los había controlado desde la época de la colonia y era el Ayuntamiento la corporación encargada de recaudar y administrar para la ciudad los ingresos que se generaban con las funciones. Por ello, estas diversiones eran al mismo tiempo, tanto una forma de especulación como de control político, por ello, los permisos y las disposiciones se reglamentaban acuciosamente a fin de ordenar este tipo de manifestaciones públicas.

Cuando el Ayuntamiento no las podía administrar porque no contaba con los fondos necesarios, las cedía en concesión a particulares, costumbre que seguía también en otros ramos importantes para su funcionamiento, como eran el alumbrado o la recolec. ción de basura. Este privilegio se estipulaba a través de las llamadas contratas, que eran las operaciones económicas usadas más frecuentemente entre los empresarios decimonónicos porque les permitían obtener ganancias sin tener que hacer grandes inversiones.

Las contratas eran el "instrumento, escritura o papel con que las partes aseguran los contratos que hacen y el mismo contrato, ajuste o convenio,

${ }^{2}$ Roch, Bosquejo, 1835 en Moreno, "Primeros", 1993, p. 100. 
especialmente cuando se trata de asientos o empresas con la Hacienda pública" ${ }^{3} \mathrm{~A}$ las personas que suministraban el servicio se las conocía entonces como asentistas, ya que hacían un asiento o contrato con el gobierno o con el público para la provisión del beneficio.

Por asentistas se entendian en los pasados tiempos a los que hoy llamamos contratistas, es decir, personas que contrataban con el rey, o con el público, proveerle de alguna cosa, como los naipes, y por extensión las que hacían otros contratos, como el de dar una cantidad fija por la plaza de gallos, siendo de su cuenta gastos y utilidades. ${ }^{4}$

Las contratas, por tanto, consistían en la asignación a un particular de servicios administrados por la corporación municipal. En este sistema, el particular hacía un negocio rentable ya que desde el establecimiento del contrato se estipulaban no sólo sus obligaciones y atribuciones, sino sus percepciones y comisiones. Estos convenios se asignaban generalmente en subasta pública por cinco años, y se afianzaban mediante un fiador de reconocida solvencia. El asentista aceptaba ciertas reglas a cambio de lucrar con su concesión y de obtener ganancias a través de los negocios que emprendía con ella, y cobraba una renta fija que el Ayuntamiento le pagaba religiosamente, muchas veces dejando de realizar obra pública u otras mejoras para la ciudad o bien hipotecando algunos ramos.

\footnotetext{
${ }^{3}$ Escriche, Diccionario, 1837, p. 155.

${ }^{4}$ Marroquí, Ciudad, 1900-1903, vol. 2, p. 462.
}

Otro actor, al que se le adjudicó la contrata para el manejo de los espectáculos, fue el general de brigada Manuel Barrera Dueñas (1780-1845), originario de la ciudad de México. Desde la independencia, gozaba del privilegio de la fabricación de los vestuarios para el ejército de la capital y, durante los años treinta, compartió con algunos de sus parientes el manejo de las contratas de limpia y de alumbrado de la ciudad, lo que nos ha llevado a considerarlo como un claro ejemplo de empresario urbano. ${ }^{5}$ Iturbidista convencido, fue regidor del Ayuntamiento en 1827, comisionado de teatros en 1830 y presidente de la Comisión del ceremonial para la colocación de las cenizas de Iturbide en la catedral en 1838. Compadre del presidente Anastasio Bustamante y estrechamente vinculado a los políticos de la época, tuvo la oportunidad de sacar provecho de las relaciones entabladas en las múltiples actividades a las que se dedicó. Entre la gama de negocios que emprendió logrando acumular una considerable fortuna, destacaron los préstamos con interés, la compraventa de bienes inmuebles en la ciudad y sus alrededores, y el objeto de este trabajo: los espectáculos.

En este último campo, Manuel Barrera se había hecho cargo, desde $1825,{ }^{6}$ del asiento del Teatro del Coliseo o Teatro Principal, donde se be. nefició con la expulsión de los espa-

\footnotetext{
${ }^{5} \mathrm{La}$ información para este artículo ha sido tomada de mi trabajo doctoral en preparación, acerca de la vida y negocios de este empresario.

"Véase "Poderoso caballero es don Dinero" en El Tocayo de Clarita, 6 de mayo de 1825 .
} 
ñoles en 1827, ya que se quedó con sus concesiones. En su carácter de asentista teatral, remodeló el Teatro Principal en 1829 y logró negociar con el Ayuntamiento el aumento de los precios del boletaje, en lo cual fungió de juez y parte, pues aprovechó su pertenencia a dicha institución para sus fines personales. Posteriormente, en 1830 , fue designado comisionado de los dos teatros que funcionaban entonces, debido a su experiencia y relaciones con los actores. Fue encargado de revitalizar los espectáculos para lograr funciones que estuvieran a la altura de una capital cada vez más cosmopolita y ansiosa de disfrutar de diversiones acordes con la ilustración de sus habitantes. ${ }^{7}$ Así, justificó la necesidad de recurrir a extranjeros para mejorar la calidad de los espectáculos alegando que el público lo merecía, y usó de sus relaciones para hacer venir de Europa actores, actrices, cantantes y bailarines que, aunque reacios a arriesgarse a la aventura en un país extraño, llegaron a inyectar entusiasmo y atractivo a las artes mexicanas.

\section{LOS GALLOS, LOS TOROS Y LOS GLOBOS}

Pero Barrera no sólo se interesó por los coliseos citadinos, sino que vio también la oportunidad de hacer negocio con los populares espectáculos de gallos y de toros.

Al serle concedida la contrata para administrar los palenques de gallos, obtuvo la facultad de armar en la capi283.

${ }^{7}$ Olavarría y Ferrari, Reseña, 1895, vol. I, p.

tal y en los pueblos del Distrito, jacalones o palenques para que se verificaran las peleas de gallos. El acuerdo especificaba que los particulares que quisieran obtener licencias para llevarlas a cabo, se habrían de entender con el asentista, quien podía cobrar por ellas la cuota que estimara conveniente. Barrera construyó, en la municipalidad de Tlalpan, una arena de gallos y una fonda anexa a la casa que allí tenía; esta plaza le redituaba entradas considerables, sobre todo cuando se celebraba la tradicional feria de Tlalpan en el mes de junio, durante la Pascua de Pentecostés. ${ }^{8}$

Por otra parte, las corridas de toros fueron uno de los espectáculos favoritos del público durante la colonia, aunque decayeron a partir de las diversas prohibiciones que algunos virreyes impusieron por considerarlas un espectáculo sangriento. Contrario a lo que se pudiera pensar, durante la independencia se verificaron algunas corridas en la plaza del Volador, cuyos beneficios se destinaron a vestir a los soldados del ejército realista ${ }^{9} y$, por lo que Manuel Barrera nos dice en una de sus comunicaciones, él fue probablemente uno de tantos asentistas de toros durante esa época, ya que menciona que el virrey Calleja presenció una de ellas. ${ }^{10}$

\footnotetext{
${ }^{8}$ Probablemente Barrera construy6 la plaza de gallos porque conocía el éxito y las ganancias que se habían obtenido desde el siglo anterior con una plaza similar construida en San Agustín de las Cuevas (Tlalpan) por oficiales reales, que dejó como ganancia 1740 pesos, en Marroquí, Ciudad, 1900-1903, vol. 2, p. 471.

${ }^{9}$ Rangel, Historia, 1924, p. 362

${ }^{10}$ Véase, La Lima de Vulcano, 27 de diciembre de 1834 , suplemento núm. 115. ¿Habrá
} 


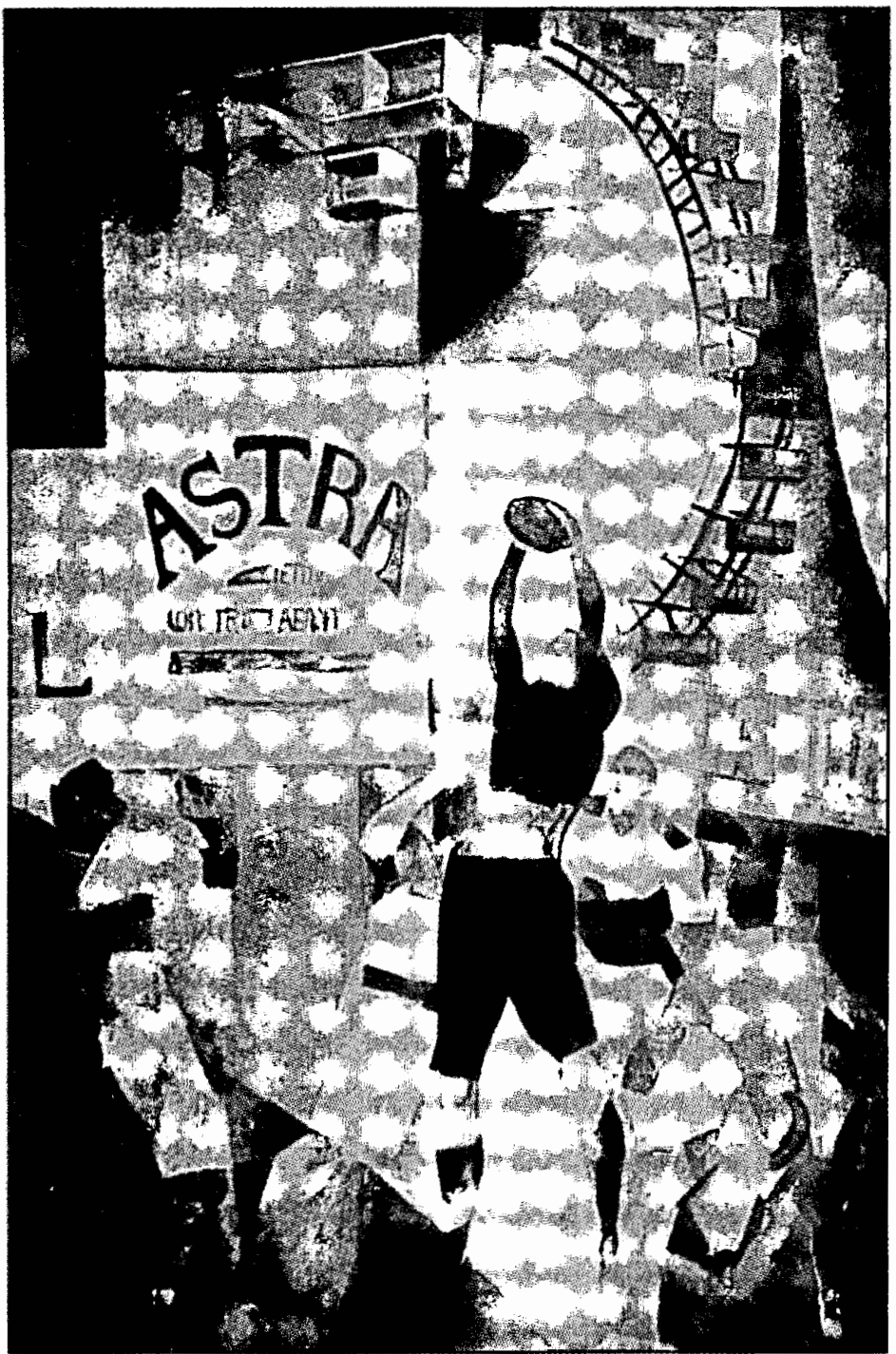


En junio de 1832 presentó una postura para encargarse del manejo de la plaza de toros de San Pablo, donde se llevarian a cabo las corridas que reseñaremos. La Real Plaza de Toros de San Pablo había sido construida de madera y mampostería en 1788 , con un cupo para 11000 espectadores. El mismo año de la consumación de la independencia, ésta se incendió y paulatinamente fue reconstruida y le tocó a Barrera reacondicionarla. Esta plaza sería la única existente en la ciudad hasta 1851, cuando se inauguró la del Paseo Nuevo o de Bucareli. En 1867, a causa de la prohibición gubernamental de celebrar corridas de toros, ambas plazas fueron demolidas, pero volverían a aparecer en 1887 , cuando el presidente Porfirio Díaz levantó la prohibición. La Plaza de San Pablo estaba situada al sureste de la ciudad, inmediata al templo del mismo nombre (entre Venezuela y San Ildefonso).

Los términos del remate que Barrera reconoció en el contrato, especificaban que se

aceptara como condición que no pudieran lidiarse toros ni darse otra clase de diversiones sino en los días festivos, y además, el empresario no tendría obligación de dar gratis sino una lumbrera en sombra para el individuo que nombrase el Ayuntamiento que presida y una grada también en sombra para la tropa del servicio, pues mientras menos lugares tenga dicho empresario que

habido alguna relación entre el hecho de que Barrera se interesara por obtener la contrata de toros, $y$ el producto del arrendamiento de la plaza se destinara a los fondos del vestuario de las tropas? dar, será mayor su ganancia y el valor del arrendamiento se aumentará. ${ }^{11}$

Barrera reconstruyó la plaza con gradas de madera como era la costumbre, en ocasiones la subarrendaba y en otras él mismo fungía como empresario. En 1836 salió a remate su contrata al haberse concluido el término del arrendamiento, al igual que la del Teatro Principal que todavía poseía. La almoneda se otorgó a Luis Ruiz de Larios por la cantidad de 510 pesos anuales y, curiosamente, Barrera quedó en calidad de fiador, ${ }^{12}$ lo que nos hace pensar que Ruiz de Larios sólo fungió como prestanombres del empresario, ya que éste no debía de seguir apareciendo como cabeza de la empresa, debido a las constantes quejas recibidas del público por las faltas de cumplimiento en que había incurrido, no sólo de moral y decencia pública, sino de falta de cuidado en las diversiones que ofrecía, ya que se le acusaba de haber "comprado para la lidia, toros de tan mala calidad que era imposible torearlos dignamente". ${ }^{13}$ El empresario se defendió minimizando el hecho de que, en la corrida, algunos toros carecieran de la feroz bravura que sus detractores esperaban; argumentaba en su favor que ello era un

pretexto, miserable por cierto, y tan distante de poderse disculpar, cuanto

11 Archivo Histórico del Distrito Federal (en adelante AHDF), Diversiones públicas, inv. 797 , exp. 86, 1841, fs.1-2.

${ }^{12}$ Archivo de Notarías (en adelante AN), Miguel Diez de Bonilla (215), vols. 1415, 1836, f. 49.

${ }^{13}$ Reyes de la Maza, Teatro, 1969, p. 36. 
que el administrador que gobierna la plaza y entiende de los asuntos concernientes a ella y sus funciones, y no yo, sólo había dicho que se lidiaron siete toros, sin recomendación particular ni exagerada; pero no habló en el cartel de que serian valientes y feroces, en virtud de lo cual no hubo engaño ni mala fe. ${ }^{14}$

Como se puede ver, la actividad de Barrera en los espectáculos populares tuvo muchos contratiempos, su nombre y fama fueron constantemente criticados y sacados a relucir en los periódicos y en las discusiones del Cabildo metropolitano, cuestión que nos permite seguir de cerca las acciones del empresario.

UN FRACASO REPETIDO: iFRAUDE!

En 1833 se le presentó a Barrera un negocio que a todas luces parecía redituable y difícil de rechazar. Consistía en traer de Cuba a un aeronauta que, mediante un globo aerostático inflado con hidrógeno, remontaría los aires de la capital. Barrera sabía que un espectáculo de este tipo tendría éxito y que la gente, ávida de emociones nuevas, acudiría en masa a presenciarlo. La noticia de que en Cuba había un francés de nombre Adolphe Theodore que se presentaba como "físico astronauta", le había sido proporcionada por uno de sus amigos actores, quien además le había mencionado las extra. ordinarias hazañas que había realizado

${ }^{14}$ La Lima de Vulcano, 27 de diciembre de 1834, suplemento núm. 115. en La Habana y en Matanzas. Decía que era experto en efectuar ascensiones en globo aerostático y que los cubanos habían pagado exorbitantes sumas por verlo.

Posteriormente se enterarian de que era un charlatán, que había servido de criado en la casa de Eugenio Robertson, famoso en Europa por haberse elevado varias veces en globo, y del cual había tomado sus "conocimien. tos". 15

Contactado Theodore, éste propu* so a Barrera formar una compañía que explotase las operaciones de ascensión en globos, ya que para llevarlas a cabo necesitaba contar con un capital inicial de 5000 pesos. Barrera, entusiasmado, decidió suministrar personal. mente el dinero que pensó le sería reembolsado con creces cuando se verificara la función, en la plaza de 'Toros de San Pablo que él administraba. Se solicitó el permiso del gobernador del Distrito Federal, quien lo proporcionó, y se iniciaron las labores de construcción del globo y los artefactos respectivos. ${ }^{16}$ El espectáculo consistiría, además del plato fuerte que era la ascensión, en presenciar la manera en que se inflaba el aparato, mientras había música y otras diversiones, hasta el momento en que el valiente aeronauta subía a enfrentar el peligro que significaba remontar los aires.

\footnotetext{
${ }^{15}$ AHDF, Diversiones públicas, inv. 797, exp. 56 , f. 28. "Sepa el general trapero quién es su amigo el globero", publicado en la Gaceta de Tampico por Antonio Alcalde, México, 1833.

${ }^{16}$ La explicación de los mecanismos y técnicas para la ascensión se pueden consultar en Maria y Campos, Navegación, 1944, y en Moreno, "Primeros", 1993.
} 
La función se concertó para el 1 de mayo de 1833, con la salvedad de si el tiempo lo permitía. Los boletos se pusieron a la venta y se agotaron rápidamente. Los precios de las entradas serían: por una lumbrera o palco con cupo de doce personas, 32 pesos, mientras que en las gradas se cobrarían dos pesos por persona y un peso en los tendidos, independientemente de si eran de sol o sombra,

advirtiendo que de ningún modo se recibirá dinero en las referidas puertas, debiendo ser la entrada con su correspondiente boleto; cada asiento de grada será numerado; y para evitar la confusión, no se dará contraseña de salida. [...] La empresa ni el aeronauta no serán responsables de los fraudes y aumento de precios de los revendedores.

Los correspondientes piquetes de tropa y los agentes comisionados al efecto por la autoridad, celarán del orden de esta floreciente república. Si su éxito corresponde a mi anhelo de complacer a mis indulgentes espectadores, habré llenado mi tarea y serán recom. pensados los desvelos y afanes de Adolfo Theodore. ${ }^{17}$

Barrera solicitó se dictaran providencias de policía, y el Ayuntamiento ordenó medidas de seguridad para evitar accidentes por medio de patrullas y dispuso la asignación de un mayor número de auxiliares que redoblaran la vigilancia, temeroso de que se presentara algún problema o accidente imprevisto en razón de la ascensión. Asimismo, dispuso la manera en que

${ }^{17}$ AHDF, Diversiones públicas, inv. 797, exp. 56,1833 , f. 2 . se debía de regular el tráfico de carros para la entrada y salida de la plaza.

El espectáculo se anunciaba como la "Sexta ascensión aerostática del físico don Adolfo Theodore, con el gran aeróstato nombrado 'El Mexicano', que se verificará el miércoles 1 de mayo a las cinco de la tarde, en la plaza principal de toros de San Pablo", y en el orden se preveía que

el festival daría inicio a las tres de la tarde con sinfonías interpretadas por la Artillería mexicana. A las cinco el aeronauta se presentará vestido de un elegante traje. A la elevación de 100 varas, el volador dejará bajar un hermoso paracaídas de tafetán conducido hasta el suelo por una águila, dedicada a Manuel Barrera, en prueba de su agradecimiento y respeto por haberle suministrado los caudales para habilitar esta función. ${ }^{18}$

El Cabildo se quejó por no haber sido tomado en cuenta para el desarrollo de la función, pues el empresario parecía haber olvidado que era el Ayuntamiento quien ejercía las funciones de orden público y control de los espectáculos. Por tanto, la corporación argumentaba que, al no haber intervenido la autoridad política en el arreglo del espectáculo, ignoraba el número de boletos vendidos y su precio, mismo que se había decidido arbitrariamente desconociendo la facultad de los funcionarios encargados al efecto, de tal suerte que el público no tenía garantía alguna de que se ejecutaría tal viaje aerostático, ni tampoco que se devolverían los muchos miles de pesos que ha-

${ }^{18}$ Ibid., f. 16. 
bían sacado con la venta de los boletos, en caso de suspenderse dicho evento. Al Ayuntamiento le preocupaba que Theodore y el empresario habían expedido boletos impresos en papel muy corriente y contraseñas falsificables sin mucho trabajo, por lo que el Cabildo manifestaba que "no será extraño que estando este negocio encargado al interés individual, la tarde del espectáculo aparezcan mayor número de boletos respecto a las personas que caben adentro de la plaza de toros". Por ello, exhortaba al gobernador del Distrito Federal a que ordenara con energía se imprimieran nuevos boletos y se le exigiera a Theodore un fiador que respondiera por la suma de pesos recibida. También se mostraba disgustado porque se le había reservado solamente la lumbrera número 19 , que se ubicaba entre las segundas de la plaza. ${ }^{19}$ eEs que acaso el Cabildo preveía de antemano problemas y quería dejar asentada su preocupación y las medidas que estaba tomando?

El día de la función ( 1 de mayo de 1833), la ascensión no se verificó a causa del clima, "que amenazaba tormenta" y ponía en peligro la seguridad del vuelo. La decisión fue comunicada a las autoridades, pero en lugar de devolver las entradas, el aeronauta propuso cambiar la fecha para el 22 de mayo. Sin embargo, Theodore aclaró que necesitaría otros 5000 pesos para construir un globo más seguro; Barrera, ya embarcado, no tuvo más remedio que proporcionárselos. Cuando los ataques en su contra arreciaron, Barrera se vio en la necesidad de justificar el

${ }^{19}$ Ibid. destino que tuvo el dinero. Decía que el producto de la venta de boletos había ascendido a 14426 pesos y que Theodore había gastado en la construcción del primer globo 8376 pesos, 6 reales y en la del segundo 6180 pesos, s/8, lo que sumaba 14556 pesos, 7 reales, 1/8, excediéndose en 130 pesos, 7 reales del total de la venta de boletos. ${ }^{20}$ Por tanto, subrayaba que era el empresario quien estaba financiando el déficit.

El Cabildo metropolitano estaba alarmado por lo que consideraba un fraude al público y a las autoridades citadinas, las quejas por las irregularidades cometidas no cesaban. Barrera se negaba a reembolsar el producto de las entradas (sólo se cambiaban las contraseñas por otras) y el aeronauta no lograba emprender el vuelo. Prevenido de que las discusiones en el Cabildo dejaban su nombre y su honra muy lastimados, Theodore contestó en una carta enviada a $\mathrm{El}$ Telégrafo, eximiéndose de las responsabilidades que se le imputaban y afirmando que

el producto de la venta de los boletos de las entradas se encontraba depositado en las saneadas arcas de Barrera hasta después de verificada la ascensión y antes de que todo individuo que gustase devolver sus boletos y recobrar su dinero ocurriese por él, como se ha verificado con varias personas y se verificará con todas en igual caso, porque es de pública notoriedad que el caudal del señor Barrera es saneado y no necesita de la suma de que se trata para el giro de su casa. ${ }^{21}$

${ }^{20}$ La Lima de Vulcano, 10 de enero de 1835 en Reyes de la Maza, Teatro, 1969, p. 340.

${ }^{21}$ El Telégrafo, 12 de mayo de 1833. 
Esta aclaración, que dejaba entrever que se harían efectivas las entradas, tuvo como consecuencia que muchas personas acudieran en masa a redimir sus boletos, encontrándose con la negativa del empresario, quien aseguraba que él en ningún momento había aceptado devolver las entradas. ${ }^{22}$

La situación se convirtió en un escándalo al grado de que, en varias sesiones de Cabildo, el asunto se discutiría de manera intermitente. Se criticaría al empresario y al aeronauta por haber pospuesto la función y se presentaron diversas quejas por la negativa a devolver el precio de las entradas. Para protegerse y estar seguro de que Theodore no era un charlatán, el cuerpo edilicio determinó pedir un dictamen a los catedráticos del Colegio de Minería, a fin de que inspeccionaran lo que Theodore estaba haciendo y constatar que cumplía con las especificaciones y asegurarse de que realizaría el vuelo en la siguiente fecha, que esta vez sería el 22 de mayo. La certificación, firmada por Manuel Ruiz de Tejada, Manuel Castro y Tomás Ramón del Moral, determinó

que el globo está concluido y en buen estado, con volumen y capacidad bastante para transportar aun mayor carga de la que se le destina, aun cuando no se le llene de gas más que las tres cuar-

\footnotetext{
22 Las cosas llegaron a tal grado que incluso se levantó una demanda por golpes en contra del empresario, interpuesta por un individuo que argumentaba había sido golpeado cuando fue a tratar de cambiar sus boletos: " $y$ han inferido entre dicho señor y sus hijos y dependientes, bofetadas al expresado". Véase AHDF, Actas de cabildo secretas, 1835
}

tas partes de su capacidad, y para la que es suficiente la provisión que tiene de hierro[...] En virtud de lo cual, creemos que si se cumple además con algunas indicaciones que le hemos hecho y los operarios proceden con la debida expedición y esmero, deberá efectuarse la elevación del globo, que sólo podrá embarazar o entorpecer una tormenta atmosférica, precisamente en el día senalado y no en los anteriores, u otra desgracia imprevista. ${ }^{23}$

El día llegó y Theodore no realizó la ascensión, que se volvió a aplazar para el día 24 en que tampoco se verificó. Entonces se incrementaron las recriminaciones. El Cabildo, en representación del pueblo, protestó por la burla de que había sido objeto el público exigiendo la devolución del dinero. No obstante las quejas levantadas, el 26 de mayo recibió el Ayuntamiento una resolución firmada por el alcalde primero, Ignacio Martínez, en donde se relevaba de responsabilidad a $\mathrm{Ba}$ rrera argumentando que el espectáculo se había anunciado como de "probable verificación", contraponiéndose y venciendo las dificultades que opusiera la naturaleza, en el caso de que éstas fueran mayores que la industria calificada del aeronauta. El documento añadía que no era posible saber, ni existían las pruebas de que Barrera hubiera estado dispuesto a la rescisión de su compromiso; la cuestión se reducía así a que, sí subía Theodore, se darían por satisfechos los espectadores, pero si no, se les habría de devolver lo que habían pagado, es decir, que los espec-

${ }^{23}$ La Lima de Vulcano, 10 de enero de 1835 en Reyes de la Maza, Teatro, 1969, p. 340. 
tadores siempre ganarían en su contrato, y el señor Barrera no. Por lo cual, concluía reconociendo que icómo podía recriminarse al general por haber aceptado financiar el ascenso ? $^{24}$

Para protegerse, Barrera metió a la cárcel a Theodore y el pleito se alargó por más de un año. Desde la cárcel, el aeronauta exigió una indemnización de 10000 pesos por daños y perjuicios, amén de explicar que de su compromiso sólo era responsable el empresario acerca del público, "siendo yo obligado de su ejecución solamente para con la empresa" ${ }^{25}$ Cada uno por su lado se eximían de la responsabilidad. Dentro del Cabildo las pugnas por jurisdicción aumentaban, ya que las quejas parecían no encontrar eco ni con las autoridades judiciales ni con el gobernador del Distrito.

Es más, el gobernador del Distrito, José María Tornel, no sólo no tomó partido por la corporación, sino que veladamente apoyó la actuación de Barrera, al no exigir el cumplimiento de las disposiciones emitidas por los juzgados o por el Ayuntamiento.

El asunto se convirtió en una "papa caliente" para todas las autoridades, al grado de que el 23 de junio de 1834 , más de un año después del tercer intento frustrado, $E l$ Basilico se hacía eco del sentir popular, publicando una agria recriminación, dirigida expresamente al Cabildo, que decía:

En el número de los asuntos municipales que a la mayor brevedad deben

${ }^{24}$ AHDF, Diversiones públicas, inv. 797, exp. 56,1833, f. 31 .

${ }^{25}$ Ibid., f. 63. llamar imperiosamente la atención de este Ayuntamiento, esperamos que tendrá presente el escandalosísimo y vergonzoso negocio de la ascensión que este indulgente público ha pagado al ciudadano Manuel Barrera, sin haber desde más de trece meses podido conseguir disfrutar de ella o que le devuelva su dinero; creemos que esta corporación, poniendo fin a este atrasado asunto, nos probará que ella no es cómplice del señor Barrera ni por cooperación ni por morosidad en sus atribuciones. Es el colmo de la indecencia, de la desfachatez y de la arbitrariedad, ver que desde tan largo tiempo la autoridad haya permitido que, con tanto descaro, un ciudadano enriquecido por la liberalidad de los habitantes del Distrito, trate de burlarse de la consideración de que es digno, como de la justicia que le asiste. ${ }^{26}$

Visiblemente disgustado, el Ayuntamiento envió al gobernador un ultimátum donde exigía se entablara una demanda en contra de Barrera para que indemnizara a los tenedores de boletos del importe de las entradas; es más, para que el público supiera que la corporación no había descuidado sus atribuciones en el asunto, mandó publicar el expediente del caso donde se subrayaba la manera en que había tomado cartas en el asunto desde la primera ascensión frustrada. La publicación incluía las medidas que había resuelto tomar:

1a. Que se excite al señor gobernador para que haga en el término perentorio de $\mathbf{2 4}$ horas, ponga a disposición del gobierno el empresario, don Manuel Barrera, la cantidad de pesos que ha en-

${ }^{26}$ Ibid., fs. 67-68. 
trado en su poder por el expendio de boletos para la ascensión aerostática de Mr. Adolfo Theodore.

2a. Que previa averiguación sobre la entrada eventual y precio arbitrario que hubo al tiempo de la función, resultando ciertos los hechos, exhiba 4000 pesos el empresario, lo que se destinará al Hospicio de Pobres o establecimientos de primeras letras.

3a. Que la devolución del valor de los boletos se haga con intervención de uno de los señores alcaldes constitucionales, uno de los señores síndicos y otra persona de la confianza del empresario, en un lugar público de las casas consistoriales, fijándose las horas para que el público ocurra al efecto.

4a. Que se proceda al arresto del coronel, don Manuel de la Barrera, como empresario de la función y, con el correspondiente sumario, lo ponga a disposición de la Comandancia general en el término de la ley. ${ }^{27}$

La publicación del expediente "Barrera" puso de manifiesto que el Ayuntamiento se eximía de intervenir en el asunto porque se le había relegado y dejaba al arbitrio de las autoridades judiciales el que ellas procesaran a $\mathbf{B a}$ rrera. En este caso resultó palpable el peso de las relaciones que él mantenía con las altas autoridades del país, en contraparte con la autoridad del Ayuntamiento, de ahí que no se inició ninguna acción legal en los tribunales y que al Ayuntamiento se lo maniató cuando quiso ejercer sus funciones. La relación entre Barrera y la corporación quedó en muy malos términos. ${ }^{28}$

\footnotetext{
${ }^{27}$ Ibid., f. 70.

${ }^{28}$ La familia Barrera tenía varios pleitos pendientes con el Ayuntamiento por la adjudi-
}

Para limpiar su nombre, en $1835 \mathrm{Ba}$ rrera contrató a otro aeronauta, Eugenio Robertson, para que realizara una ascensión en globo. Robertson, que se encontraba en Estados Unidos, aceptó viajar a la ciudad de México si se le pagaban 10000 pesos por cada vuelo. El empresario respondió que, para protegerse de las contingencias, le daría el dinero al día siguiente de cada ascensión que fuera exitosa.

Al anunciar el espectáculo se insertó una advertencia sobre los boletos anteriores indicando que

todas las personas que tengan boletos de los que debieron servir para la última función que se desgració, pueden entrar con ellos, bajo el concepto que tengan las dos marcas y la firma con que se resellaron. Los que habiendo poseído estos boletos los hayan roto, perdido o extraviado, hoy no tienen derecho para hacer ningún reclamo.

Hábil táctica de Barrera, pues, ¿quién habría guardado boletos por más de un año y medio?

El 12 de febrero de 1835, a las 9 de la mañana, la plaza de toros de San Pablo volvió a llenarse y los asistentes fueron testigos de cómo un globo se elevaba lentamente por los aires capitalinos en medio del silencio estupefacto de la multitud. Robertson soltó el lastre y el globo se elevó de prisa hasta casi perderse de vista. Luego, un golpe de viento lo desvió y el espectáculo terminó en menos de diez minutos. Por las noticias en los periódicos, sabemos que descendió "sobre un

cación de las contratas de Alumbrado y de Limpia. 


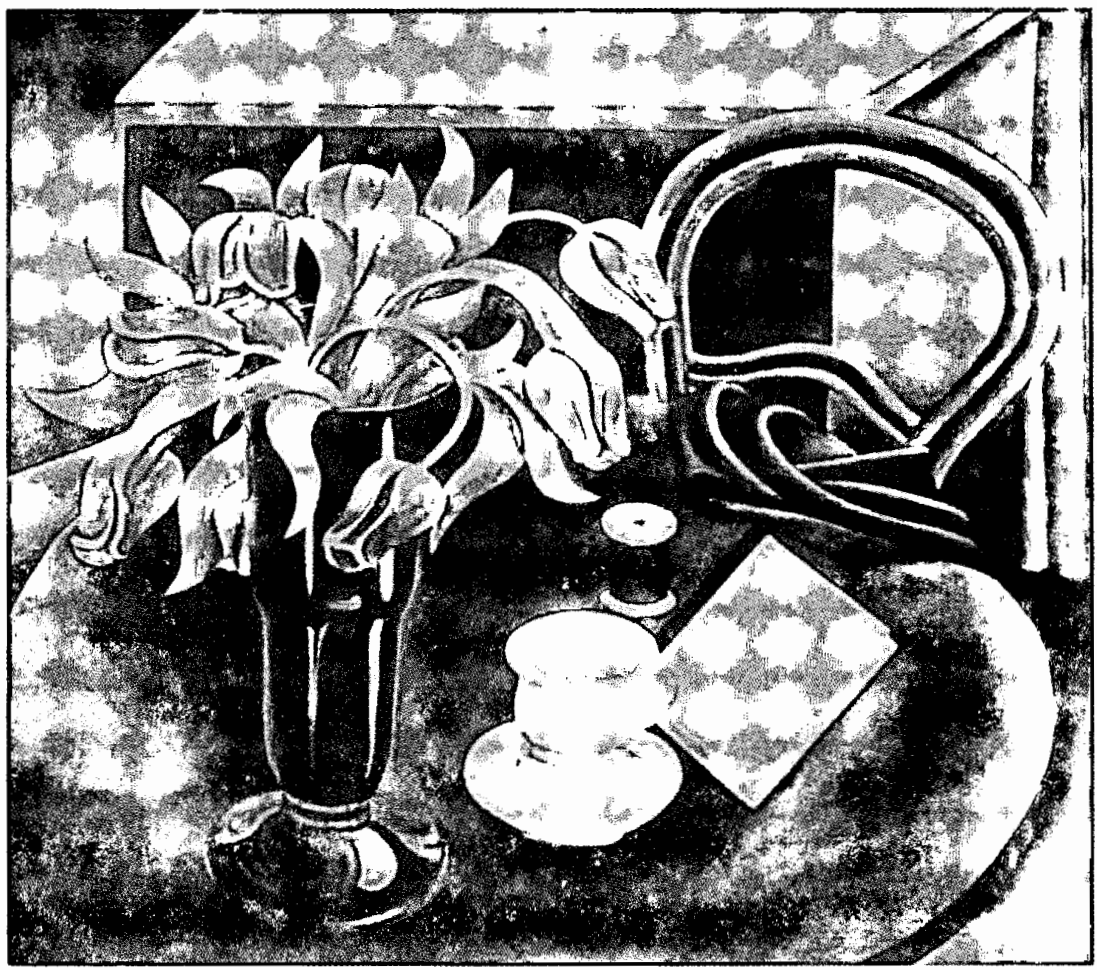

árbol a las inmediaciones de Chalma, y ahí recibió auxilio para su regreso". ${ }^{29}$ Robertson anunció una ascensión más, el 22 de marzo, que tuvo que posponerse para el 5 de abril, y que a causa del viento que inutilizó el globo, tam-

${ }^{29}$ La Lima de Vucano, 14 de febrero de 1835. La reseña que presenta Armando de Maria y Campos es por demás ilustrativa, sobre todo por la manera en que se detuvo la vida y los negocios en la ciudad a causa del espectáculo. poco se pudo efectuar. Por fin la volvió a anunciar para el 13 de septiembre, ${ }^{30}$ cuando estaría acompañado de una bella señorita que aventaría flores a los espectadores:

${ }^{30}$ En esta ocasión, los precios que Manuel Barrera cobró por asistir al espectáculo fueron:

Sombra: lumbreras con doce entradas, 18 pesos; gradas y plaza, un peso cuatro reales; tendido, un peso. Sol: lumbreras con doce entradas, doce pesos; gradas y plaza, un peso; tendido, cuatro reales. 
Lo cierto es que la ascensión se efectuó el 11 de octubre y, en efecto, lo acompañó una joven mexicana cuyo nombre quedó oculto, con lo que perdemos la posibilidad de exaltar en algo el valor de la primera aeronauta nacional, anterior a los varones. ${ }^{31}$

De esta manera, Barrera logró entradas espectaculares en el tiempo en que Robertson estuvo en la capital, y con esto terminó el sainete de los vuelos en globo durante la década de los treinta y el buen nombre del empresario quedó a salvo, por lo menos con el público, ya que al año siguiente Robertson todavía no cobraba parte de sus honorarios, y por ello nombró un representante que acudiera a los tribunales a finiquitar las cuestiones y puntos que habían quedado pendientes con el general Barrera y que exigiera:

al citado señor general, los 2300 pesos que quedaron en su poder en calidad de depósito hasta tanto se decida si los debía pagar el otorgante por las dos ocasiones que ocupó la Real Plaza de Toros de San Pablo y no tuvo efecto la ascensión. ${ }^{32}$

Amén de haber sido un espectáculo que interesó a la población de la ciudad de México, este asunto tendría que analizarse tomando en cuenta varias aristas. Por un lado, el fraude al público que pagó por una función que nunca se verificó y que, por tanto, fue engañado al no restituírsele el precio pagado.

\footnotetext{
${ }^{31}$ Moreno de los Arcos, "Primeros", 1993, p. 104 .

${ }^{32}$ AN, Fermín Villa (719), 1836, vol. 4832.
}

Por el otro, la relación conflictiva suscitada entre el Ayuntamiento y un contratista de espectáculos que, aprovechando la flexibilidad de su contrato, se permitió organizar espectáculos fuera del control de las autoridades municipales y, por último, las relaciones entre el gobernador del Distrito y un personaje dedicado a la especulación amparado en sus relaciones personales. A José María Tornel le interesaba más apoyar a su amigo y socio que enfrentar y llevar a cabo las denuncias que el Cabildo exigía.

Por último, la actuación de Manuel Barrera hay que enmarcarla dentro del amplio contexto de su actividad empresarial y de su modus operandi, donde también fue muy criticado por hacer valer sus relaciones y su fuero. Las actividades empresariales de este individuo no siempre estuvieron apegadas a la legalidad, y muchas de ellas se beneficiaron del conocimiento que tenía de la manera de proceder del Ayuntamiento.

El clima de inestabilidad política que entonces vivía el país, aunado a la desorganización político-administrativa que imperaba en la ciudad, permitió que individuos como Barrera desarrollaran diferentes actividades empresariales que no siempre iban en beneficio del público que asistía a ellas. La estafa del primer vuelo en globo es sólo un pequeño ejemplo de la actividad de un hombre que se movió y aprovechó la buena disposición de los habitantes de una ciudad que, aunque fuera un día, creyeron estar a la altura de la modernidad por el sólo hecho de alzar los ojos al cielo. 


\section{ARCHIVOS}

AHDF Archivo Histórico del Distrito Federal.

AN

Archivo de Notarías de la Ciudad de México.

\section{HEMEROGRAFÍA}

-El Telégrafo, 1833, México. xico.

-La Lima de Vulcano, 1834, 1835, Mé-

\section{BIBLIOGRAFÍA}

-Escriche, Joaquín, Diccionario razonado de legislación civil, penal, comercial y forense o sea resumen de las leyes, usos, prácticas y costumbres, como asimismo de las doctrinas de los jurisconsultos, dispuesto por orden alfabético de materias, notas de Juan Rodríguez de San Miguel, Oficina de Galván a cargo de Mariano Arévalo, México, 1837.

-Maria y Campos, Armando de, La navegación aérea en México, Cía. de Ediciones Populares, México, 1944.
-Marroquí, La ciudad de México, Tipografía y Litografía la Europea, México, 1900-1903, 3 vols.

-Moreno de los Arcos, Roberto, "Ios primeros aeronautas en México: Adolphe Theodore (1833-1835) vs. Eugenio Robertson (1835)", Tempus. Revista de Historia de la Facultad de Filosofia y Letras, núm. 1, otoño de 1993.

- Olavarría y Ferrari, Enrique de, Reseña bistórica del teatro en México, Imprenta La Europea, 2a. ed., México, 1895, vol. I.

-Rangel, Nicolás, Historia del toreo en México. Época colonial. (1529-1821), Imprenta Manuel León Sánchez, México, 1924.

-Reyes de la Maza, Luis, El teatro en México durante la independencia (18101839), Instituto de Investigaciones Estéticas-UNAM, México, 1969 (Estudios y Fuentes de Arte en México).

Roch, E., Bosquejo de los viajes aéreos de Eugenio Robertson en Europa, los Estados Unidos y Las Antillas, trad. de José Ma. Heredia, Imprenta de Galván a cargo de Mariano Arévalo, México, 1835. 


\section{SECUENCIG}

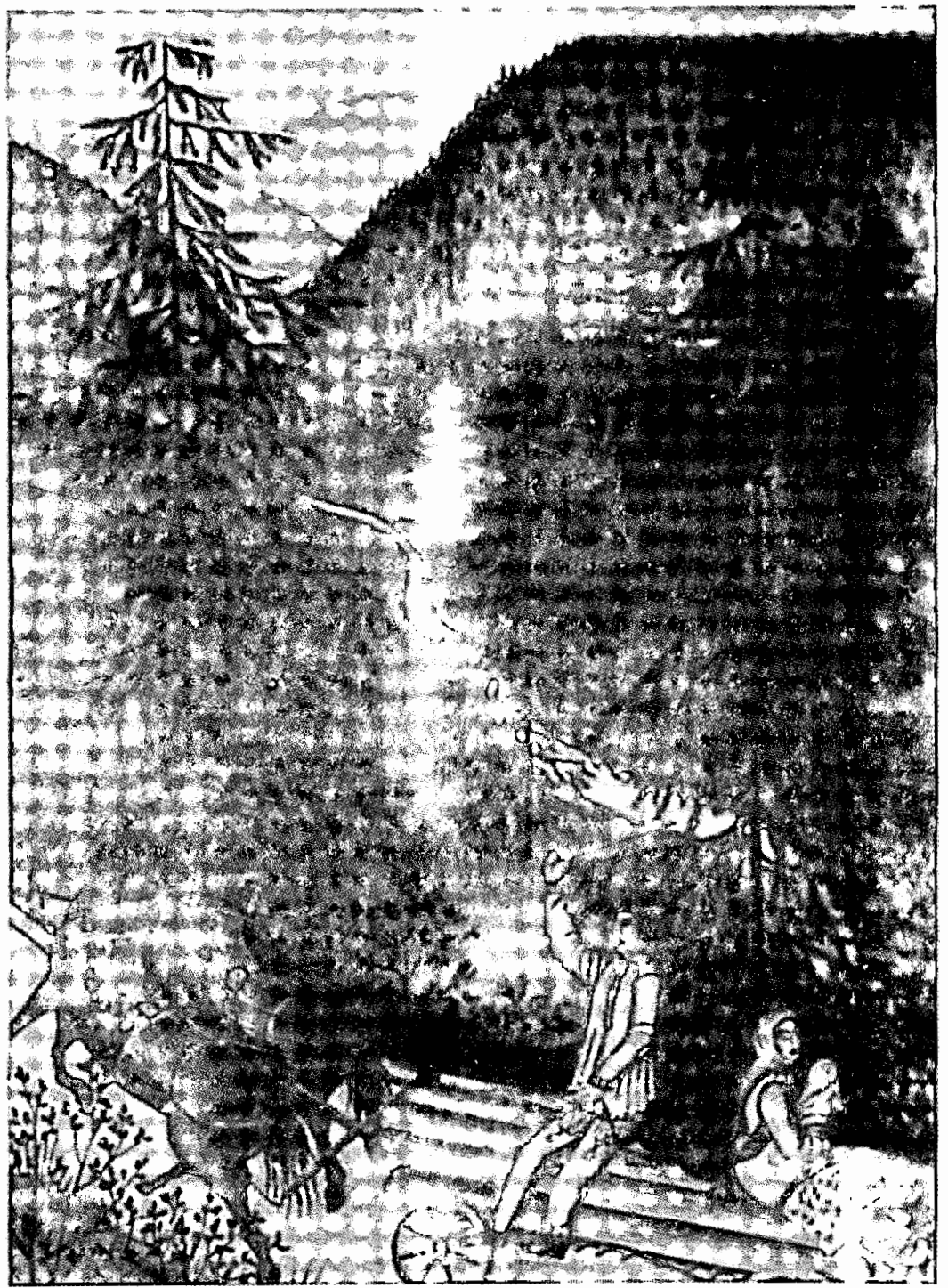

